\title{
Neuro-mediators as predictors of paediatric atopic dermatitis
}

\author{
I. J. Wang ${ }^{* \dagger}$, W. S. Hsieh ${ }^{\ddagger}$, Y. L. Guo ${ }^{\S}$, S. H. Jee ', C. J. Hsieh ${ }^{\dagger}$, Y. H. Hwang ${ }^{\dagger}$ and P. C. Chen \\ * Department of Pediatrics, Taipei Hospital, Department of Health, ${ }^{\dagger}$ Institute of Occupational Medicine and Industrial Hygiene, National Taiwan University College of \\ Public Health, Taipei, Taiwan, ${ }^{\ddagger}$ Department of Pediatrics, ${ }^{\S}$ Department of Environmental and Occupational Medicine, National Taiwan University Hospital and \\ National Taiwan University College of Medicine, Taipei, Taiwan and "Department of Dermatology, National Taiwan University Hospital, Taipei, Taiwan
}

\section{Clinical and Experimental Allergy}

Correspondence:

Professor Pau-Chung Chen, Institute of Occupational Medicine and Industrial Hygiene, National Taiwan University College of Public Health, Room 733, 17 Syujhou Road, Taipei 10055, Taiwan. E-mail: pchen@ntu.edu.tw, r92846001@ntu.edu.tw

\section{Summary}

Background Attempts to identify predictors of atopic dermatitis (AD) have focused on genetic and immunologic factors. However, the role of neuro-mediators remains to be elucidated. Objective To evaluate nerve growth factor (NGF) and vaso-active intestinal peptide (VIP) in predicting paediatric $\mathrm{AD}$ and assess their correlation with intrinsic and extrinsic types of $\mathrm{AD}$. Methods We performed a nested case-control study in the prospective Taiwan birth panel cohort study. Cord and maternal plasma and questionnaires were gathered at birth. During follow-up, we identified 40 available AD cases, which were matched to 80 unaffected controls chosen from this cohort. The concentrations of IgE, NGF, and VIP in cord and maternal plasma of these subjects were performed by ELISA. Receiver-operating characteristic (ROC) curves were generated to see how well each biomarker could predict AD.

Results The NGF levels were significantly higher in AD patients than controls (mean $\pm \mathrm{SD}$ : $65.47 \pm 44.45$ vs. $49.21 \pm 12.18 \mathrm{pg} / \mathrm{mL}$ for cord plasma and $89.68 \pm 41.04 \mathrm{vs}$ $66.96 \pm 23.05 \mathrm{pg} / \mathrm{mL}$ for maternal plasma) $(P<0.05)$. VIP levels were also higher but not statistically significant. Plasma NGF may be a better biomarker than IgE in detecting paediatric AD (area under the ROC curve $=0.65$ vs. 0.61 for cord plasma and 0.69 vs. 0.61 for maternal plasma). Maternal NGF levels were significantly higher in patients with both intrinsic $(96.18 \pm 48.15 \mathrm{pg} / \mathrm{mL})$ and extrinsic $(86.18 \pm 37.23 \mathrm{pg} / \mathrm{mL})$ types of AD compared with controls $(66.96 \pm 23.05 \mathrm{pg} / \mathrm{mL})(P<0.05)$. We assessed a significant correlation between self-reported stress during pregnancy and maternal NGF levels $(r=0.22, P=0.02)$. Conclusion Our results suggest that NGF is a good alternative biomarker in predicting children with a risk of $\mathrm{AD}$

Keywords atopic dermatitis, intrinsic, maternal stress, nerve growth factor Submitted 20 November 2007; revised 11 January 2008; accepted 8 April 2008.

\section{Introduction}

Atopic dermatitis (AD) is a chronic relapsing inflammatory skin disease. Based on IgE-mediated sensitization, AD is divided into two types: intrinsic and extrinsic. In contrast to the intrinsic type, extrinsic $\mathrm{AD}$ exhibits high serum IgE levels, allergen-specific IgE to aeroallergens and food, positive skin prick reaction, and a positive history of allergic rhinitis (AR) and asthma [1].

Evidence suggests that the nervous system can influence the course of AD through emotional stress [2], altered patterns of cutaneous innervation, and abnormal expression of neurotrophin and neuropeptides in skin lesions [3, 4]. Numerous studies have shown that nerve growth factor
(NGF), the best-characterized member of the neurotrophin family, modulates the allergic response through interactions with immune-inflammatory cells. NGF may also stimulate nerve fibres and modulate the synthesis of neuropeptides [3-5].

Neuropeptides have important modulatory effects on immune cells, especially on Th1/Th2 balance with a correlation to allergic sensitization and cytokine release in children [6, 7]. Vaso-active intestinal peptide (VIP), a kind of neuropeptide, has various effects on vasodilatation, sub-mucosal gland secretion, facilitation of cholinergic neurotransmission, and stimulation of mast cells, lymphocytes, and eosinophils [4]. Dermal contacts between mast cells and nerves are increased in $\mathrm{AD}$ skin 
compared with non-atopic controls [8], suggesting the maintenance of neurogenic inflammation through activation by neuropeptides.

Recent studies have shed light on the interactions of genetic, environmental, immunologic factors (i.e. cytokines) and immunoglobulin receptors, and polyunsaturated fatty acids, which contribute to the development of AD. Nevertheless, the role of neuro-mediators and neuroimmune regulation in $\mathrm{AD}$ has not been clarified [9-11]. Because the onset of $\mathrm{AD}$ is relatively early in life, identification of pre-natal and early childhood biomarkers is of critical importance. Therefore, this study aimed to investigate whether blood neuro-mediators NGF and VIP can predict paediatric $\mathrm{AD}$ and assess their association with intrinsic and extrinsic types of AD.

\section{Methods}

\section{Study population}

This was a nested case-control study conducted from 2004 to 2006 in the prospective Taiwan birth panel cohort study. Subjects were recruited from medical centres, regional hospitals, local hospitals, and clinics in Taiwan considering potential environmental exposure and nation-wide representation in 2004. Pregnant women in their third trimester of pregnancy who had a pre-natal examination in the selected hospitals were invited to join. Cord blood was collected at delivery. A total of 328 mother and newborn pairs were recruited. Informed consents were obtained and the study was approved by the Joint Institution Review Board in Taiwan.

Cases of $\mathrm{AD}$ were defined by the International Study of Asthma and Allergies in Childhood (ISAAC) questionnaire, maternal report of doctor-diagnosed $A D$, and recurrent rash for at least four consecutive half-months periods over elbow creases, behind the knees, face, wrists, or generalized (four or more localizations). As described elsewhere, a dermatologist examined a subgroup of the participating infants, and the combination of answers that resulted in the highest sum of sensitivity and specificity was determined [12-14]. Control subjects were apparently healthy study participants who remained free of $\mathrm{AD}$ during follow-up. Patients with extrinsic AD were defined as having a positive history of intermittent AR or asthma and IgE-mediated sensitization to at least three out of 10 common allergens, while intrinsic type of $\mathrm{AD}$ was defined by the absence of any history of AR or asthma and no IgEmediated sensitization to allergens [1]. Exclusion criteria included multiple gestation (e.g. twins, triplets), inability to answer questions in Chinese, and plan to move out of the area before delivery.

During follow-up, we identified 40 available AD cases. Two control subjects from the cohort were matched to each case subject by gender, age (within 5 months), and enrollment time (within 3 months). The concentrations of IgE, NGF, and VIP in cord and maternal plasma of these subjects were performed.

\section{Questionnaire survey}

Information regarding the parents included birth year, educational level, occupation, family income, parental history of atopic diseases (such as AD, AR, or asthma), history of active smoking and environmental tobacco smoke (ETS) exposure, and maternal stress during pregnancy. The levels of self-reported maternal stress were 'never', 'seldom', 'occasionally', 'often', 'mostly', and 'regularly'. Questions of self-reported psychosocial stress were selected from 'the modified Chinese version of Short Form 36 Health Survey' (IQOLA SF-36 Taiwan standard Version 1.0; Copyright 1995 New England Medical Centre Hospital Inc.).

From the records of the cooperating hospitals, neonatal health data at birth obtained included head circumference, birth body weight, height, weeks of gestation, and type of delivery. At 2 years of age, the ISAAC questionnaire was performed and post-natal information, such as duration of breastfeeding and infant formula, early consumption of highly allergenic foods such as egg, soy bean, or shrimp before 1 year of age, furry pets and older siblings at home, fungi at house walls, and post-natal ETS exposure, was asked.

\section{Laboratory methods}

After gathering maternal and cord blood, specimens were immediately centrifuged and properly stored at $-80^{\circ} \mathrm{C}$. Samples of healthy control subjects were taken at timepoints corresponding to the disease groups to control for possible age- and time-dependent degradation of NGF concentrations between case and control subjects. Age and storage of the samples did not have a significant impact on NGF levels during the study.

Immunoglobulin E antibody analysis. The Pharmacia UniCap IgE assay test system (Pharmacia Diagnostics, Uppsala, Sweden) was used to determine the levels of cord serum total IgE. CAP test results of $0.35 \mathrm{kU} / \mathrm{L}$ or greater were regarded as a positive indicator.

Determination of neuro-mediator levels. NGF levels were measured by a highly sensitive, sandwich ELISA that recognizes human NGF and was capable of detecting concentrations of NGF as low as $16 \mathrm{pg} / \mathrm{mL}$. All procedures were performed using a commercial ELISA kit for NGF (PeproTech, Rocky Hill, USA). Briefly, polystyrene 96-well microtube immunoplates were coated with affinity-purified rabbit anti-human NGF antibody and incubated overnight at room temperature. After washing the plate 
four times, parallel wells were coated with $300 \mu \mathrm{L}$ block buffer (1\% bovine serum albumin) for the evaluation of non-specific signals. After incubating for $1 \mathrm{~h}$ at room temperature and washing, samples and standard solutions $(0-2000 \mathrm{pg} / \mathrm{mL})$ were added and the plates were incubated overnight at $4{ }^{\circ} \mathrm{C}$. After extensive washing, biotinylated detection antibody (PeproTech, Rocky Hill, USA) was added to each well and the plates were incubated at room temperature for $2 \mathrm{~h}$. Following an additional four washes, avidin peroxidase (PeproTech, Rocky Hill, USA) was added and the plates were incubated for $30 \mathrm{~min}$ at room temperature. The enzyme substrate 2'-azino-bis (3-ethylbenzothiazoline-6-sulphonic acid) (Sigma, USA) was added and incubated at room temperature for colour development. Optical density was determined using an ELISA plate reader set at $405 \mathrm{~nm}$ and the values of standards and samples were corrected by subtracting the background value due to non-specific binding. All groups compared were measured in the same assay in triplicate for each subject to reduce the influence of unavoidable interassay variances. Plasma VIP levels were measured using the peptide enzyme immunoassay kit of Peninsula Laboratories (San Carlos, USA), according to the manufacturer's protocol. Detection limit was at $8 \mathrm{pg} / \mathrm{mL}$.

\section{Statistical analysis}

The biomarkers followed a nearly normal distribution. Baseline characteristics were compared between case and control subjects with a mixed-effect model for continuous variables or conditional logistic regression for categorical variables. To assess the correlation of NGF levels and types of $\mathrm{AD}$, and the correlation of NGF levels and maternal stress, Pearson's correlation was performed.

Receiver-operating characteristic (ROC) curves, using total IgE as the standard, were generated to assess how well each biomarker could predict subsequent $\mathrm{AD}$ by sensitivity and specificity, and to see which cut-off point would provide the highest positive predictive value. All hypothesis testing were two-sided at the significance level of 0.05 and performed with the SAS software version 8.2.

\section{Results}

Nerve growth factor, vaso-active intestinal peptide, and Immunoglobulin $E$ in atopic dermatitis

Plasma samples from 40 case subjects and 80 matched control subjects were available. There were no significant differences in the characteristics between case and controls (Table 1). The mean of maternal blood NGF, VIP, and IgE levels was higher than those of cord blood (Table 2). The mean of maternal and cord blood NGF levels was significantly higher in $\mathrm{AD}$ patients than in controls $(P<0.05)$. VIP and IgE levels were also higher but not
Table 1. Characteristic of the study population

\begin{tabular}{|c|c|c|}
\hline Characteristic & $\begin{array}{l}\text { Case } \\
(N=40)\end{array}$ & $\begin{array}{l}\text { Control } \\
(N=80)\end{array}$ \\
\hline \multicolumn{3}{|l|}{ Mother } \\
\hline \multicolumn{3}{|l|}{ Maternal age (years old) } \\
\hline Mean \pm SD & $31.83 \pm 4.12$ & $27.56 \pm 5.27$ \\
\hline \multicolumn{3}{|l|}{ Maternal education, $N(\%)$} \\
\hline High school and below & $20(50.0)$ & $45(56.3)$ \\
\hline College and above & $18(45.0)$ & $34(42.5)$ \\
\hline Missing & $2(5.0)$ & $1(1.2)$ \\
\hline Maternal history of atopy, $N(\%)$ & $8(20.0)$ & $12(15)$ \\
\hline \multicolumn{3}{|l|}{$\begin{array}{l}\text { Maternal self-reported stress } \\
\text { during pregnancy, } N(\%)\end{array}$} \\
\hline Never/seldom & $16(40.0)$ & $42(52.5)$ \\
\hline Occasionally/often & $13(32.5)$ & $22(27.5)$ \\
\hline Mostly/regularly & $11(27.5)$ & $14(17.5)$ \\
\hline Missing & 0 & $2(2.5)$ \\
\hline \multicolumn{3}{|l|}{ Children } \\
\hline \multicolumn{3}{|l|}{ Birth weight (g) } \\
\hline Mean \pm SD & $\begin{array}{c}3245.10 \pm \\
498.18\end{array}$ & $\begin{array}{c}3146.78 \pm \\
434.08\end{array}$ \\
\hline \multicolumn{3}{|l|}{ Gestational age (weeks) } \\
\hline Mean \pm SD & $38.60 \pm 1.96$ & $38.56 \pm 1.52$ \\
\hline \multicolumn{3}{|l|}{ Environmental factors } \\
\hline $\begin{array}{l}\text { Duration of breastfeeding } \\
\geqslant 6 \text { months, } N(\%)\end{array}$ & $11(28.9)$ & $26(33.8)$ \\
\hline Older siblings $\geqslant 2, N(\%)$ & $18(47.4)$ & $45(57.0)$ \\
\hline Pet raising, $N(\%)$ & $7(17.5)$ & $21(26.9)$ \\
\hline Carpets at home, $N(\%)$ & $4(10.0)$ & $11(13.8)$ \\
\hline Fungi at house wall, $N(\%)$ & $11(27.5)$ & $18(22.8)$ \\
\hline $\begin{array}{l}\text { ETS exposure during pregnancy, } \\
N(\%)\end{array}$ & $8(20.5)$ & $22(27.8)$ \\
\hline Postnatal ETS exposure, $N(\%)$ & $10(26.3)$ & $28(36.8)$ \\
\hline \multicolumn{3}{|l|}{$\begin{array}{l}\text { Family income per year (NT } \\
\text { dollars), } N(\%)\end{array}$} \\
\hline$<600000$ & $7(17.5)$ & $20(25.0)$ \\
\hline $600000-1500000$ & $21(52.5)$ & $48(60.0)$ \\
\hline$>1500000$ & $10(25.0)$ & $10(12.5)$ \\
\hline Missing & $2(5.0)$ & $2(2.5)$ \\
\hline
\end{tabular}

ETS, environmental tobacco smoke; NT dollars, New Taiwan dollars; SD, standard deviation.

statistically significant (Table 2). Cord blood NGF levels were positively although statistically insignificantly correlated with maternal blood ( $r=0.17, P=0.06)$.

\section{Receiver-operating characteristic curve analysis}

Because only NGF showed a significant increase in $\mathrm{AD}$ subjects, we generated ROC curves to see how well cord and maternal plasma NGF levels could predict subsequent $\mathrm{AD}$ (Fig. 1). Cord blood NGF may be a better biomarker than cord blood IgE in predicting paediatric AD before 2 years of age [area under the curve (AUC) $=0.65>0.61$ ] (Fig. 1a). The highest positive predictive value of 52.8\% was achieved with a cut-off point of $59 \mathrm{pg} / \mathrm{mL}$. This 
Table 2. Comparison of neuromediators and IgE levels in cord and maternal blood in case and control

\begin{tabular}{|c|c|c|c|}
\hline & Number & Cord blood & Maternal blood \\
\hline & & NGF mean \pm SD $(\mathrm{pg} / \mathrm{mL})$ & \\
\hline Total & 120 & $54.37 \pm 27.84$ & $74.17 \pm 31.62$ \\
\hline $\mathrm{AD}$ & 40 & $65.47 \pm 44.45$ & $89.68 \pm 41.04$ \\
\hline Controls & 80 & $49.21 \pm 12.18$ & $66.96 \pm 23.05$ \\
\hline$P$ value $^{\dagger}$ & & $0.030^{*}$ & 0.002 \\
\hline \multirow[t]{2}{*}{$P$ value ${ }^{\ddagger}$} & & $0.003 *$ & $<0.001^{*}$ \\
\hline & & VIP mean \pm SD $(p g / m L)$ & \\
\hline Total & 120 & $20.61 \pm 8.86$ & $32.18 \pm 41.29$ \\
\hline $\mathrm{AD}$ & 40 & $23.76 \pm 26.15$ & $42.73 \pm 48.89$ \\
\hline Controls & 80 & $19.15 \pm 28.32$ & $27.28 \pm 36.52$ \\
\hline$P$ value ${ }^{\dagger}$ & & 0.084 & 0.442 \\
\hline \multirow[t]{2}{*}{$P$ value $e^{\ddagger}$} & & 0.056 & 0.442 \\
\hline & & $\mathrm{IgE}$ mean $\pm \mathrm{SD}(\mathrm{kU} / \mathrm{L})$ & \\
\hline Total & 117 & $1.51 \pm 9.21$ & $73.33 \pm 108.75$ \\
\hline $\mathrm{AD}$ & 37 & $1.90 \pm 11.05$ & $92.10 \pm 99.22$ \\
\hline Controls & 80 & $0.63 \pm 1.19$ & $64.43 \pm 112.51$ \\
\hline$P$ value ${ }^{\dagger}$ & & 0.478 & 0.214 \\
\hline$P$ value $\mathrm{e}^{\ddagger}$ & & 0.478 & 0.214 \\
\hline
\end{tabular}

${ }^{*} P<0.05$.

${ }^{\dagger} P$ value was obtained by independent $t$-test.

${ }^{\ddagger} P$ value was obtained by mix model.

SD, standard deviation; NGF, nerve growth factor; VIP, vasoactive intestinal peptide; $\mathrm{AD}$, atopic dermatitis.

cut-off point had a sensitivity of 53\% and a specificity of $80 \%$. Maternal blood NGF may be a better biomarker than maternal blood IgE in predicting paediatric $\mathrm{AD}$ (AUC $=0.69>0.61$ ) (Fig. 1b). The highest positive predictive value of $48.4 \%$ was achieved with a cut-off point of $72 \mathrm{pg} / \mathrm{mL}$, which had a sensitivity of $64 \%$ and a specificity of $75 \%$.

Correlation of nerve growth factor levels with types of atopic dermatitis

Cord NGF levels were higher in patients with intrinsictype $\mathrm{AD}$ compared with controls $(P=0.001)$ (Fig. 2a). The mean and standard deviation of cord NGF levels among the control, intrinsic $\mathrm{AD}$, and extrinsic $\mathrm{AD}$ were $49.21 \pm 12.18,78.52 \pm 69.01$, and $58.44 \pm 21.42(\mathrm{pg} / \mathrm{mL})$, respectively. There was a correlation of cord NGF levels and intrinsic type of $\mathrm{AD}(r=0.19, P=0.03)$.

Maternal NGF levels were significantly higher in patients with both intrinsic and extrinsic AD compared with controls $(P<0.05)$ (Fig. 2b). The mean and standard deviation of maternal NGF levels among the control, intrinsic $\mathrm{AD}$, and extrinsic $\mathrm{AD}$ were $66.96 \pm 23.05$, $96.18 \pm 48.15$, and $86.18 \pm 37.23(\mathrm{pg} / \mathrm{mL})$, respectively. Maternal blood NGF levels were also significantly correlated with intrinsic and extrinsic types of $\mathrm{AD}(r=0.30$, $P=0.001$ ). (a)

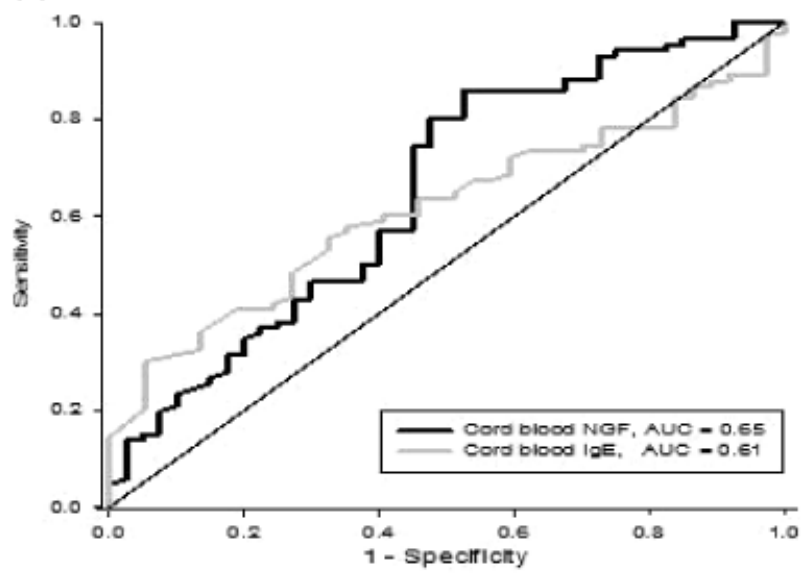

(b)

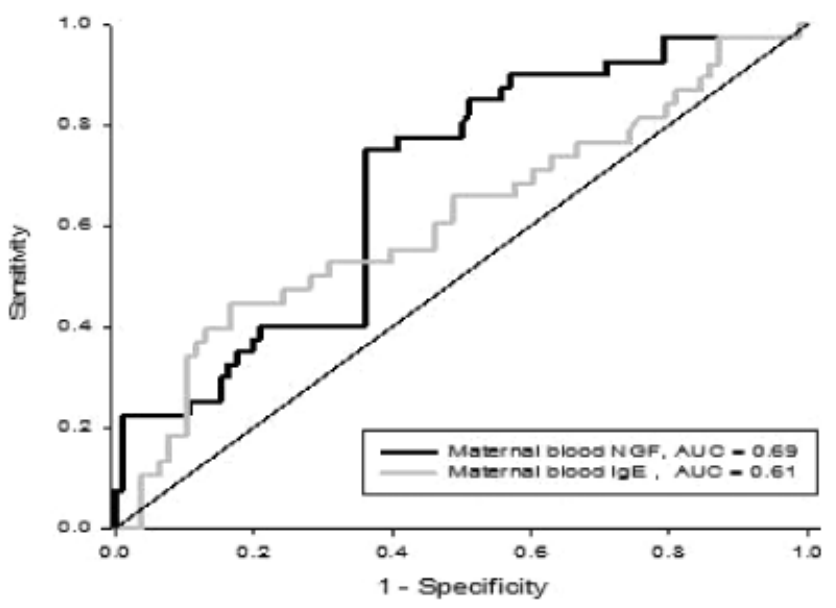

Fig. 1. Receiver-operating characteristic (ROC) curves of paediatric atopic dermatitis (AD) predicted by nerve growth factor (NGF) and IgE in cord and maternal blood. (a) The ROC area is 0.65 (95\% CI 0.55-0.76) for cord blood NGF data and 0.61 (95\% CI 0.51-0.72) for cord blood IgE data. (b) The ROC area is 0.69 (95\% CI 0.59-0.78) for maternal blood NGF data and 0.61 (95\% CI 0.49-0.72) for maternal blood IgE data. AUC, area under the curve; $\mathrm{CI}$, confidence interval.

\section{Correlation of nerve growth factor levels with maternal stress}

There was a significant correlation between maternal selfreported stress during pregnancy and maternal NGF levels $(r=0.22, P=0.02)$, while cord blood NGF levels showed no significant positive correlation $(r=0.07, P=0.44)$. There was a correlation of maternal VIP levels and maternal stress $(r=0.20, P=0.03)$ but not for cord blood VIP levels $(r=0.11, P=0.25)$.

\section{Discussion}

Attempts to identify parameters predictive of the development of $\mathrm{AD}$ have been made by many investigators to 


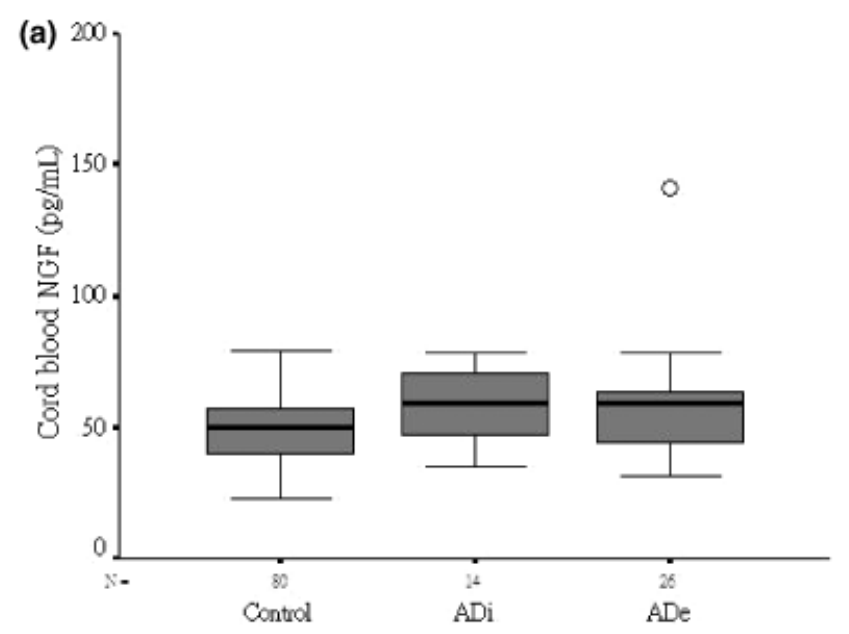

(b)

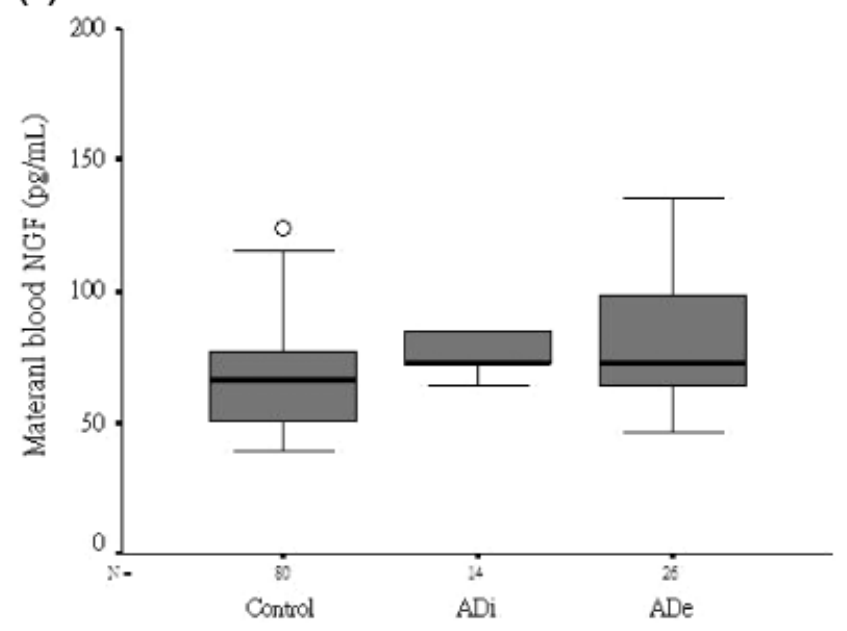

Fig. 2. Increased cord blood (a) and maternal blood (b) NGF in patients with intrinsic $\mathrm{AD}(\mathrm{ADi})$ and extrinsic $\mathrm{AD}(\mathrm{ADe})$ compared with no $\mathrm{AD}$ patients. Box plot graphs display the median (line within the box) interquartile range (edge of box). (a) Control vs. $\mathrm{ADi}(P=0.001)$; control vs. ADe (not significant); ADi vs. ADe (not significant). (b) Control vs. ADi $(P=0.003)$; control vs. ADe $(P=0.013)$; ADi vs. ADe (not significant). $\mathrm{NGF}$, nerve growth factor; $\mathrm{AD}$, atopic dermatitis.

start preventive strategies at an early stage [15]. While previous studies only investigated the association of NGF and $\mathrm{AD}$ activity [10,11], our study showed for the first time that cord and maternal plasma NGF levels were better predictors of paediatric $\mathrm{AD}$ than IgE before 2 years of age. Cord blood IgE levels were initially believed to be predictive of the development of allergic diseases [16]. However, several groups have failed to find such an association [17] and there was a general agreement that cord blood IgE, used as a single test, was not suitable as a sensitive allergy routine risk screening instrument [18, 19]. Depending on the cut-off level, the positive predictive value for atopy of cord IgE has ranged between 20 and $50 \%$, with an extremely low sensitivity of $10-20 \%$ [19-21]. Therefore, our result suggests that cord blood $\mathrm{IgE}$ is insufficient to detect individuals at risk of $\mathrm{AD}$ and more sensitive markers, such as NGF, may serve as a good substitute.

Consistent with previous studies, the means of maternal and cord blood neuro-mediator levels were higher in $\mathrm{AD}$ patients than in controls $[9,10]$. Toyoda et al. demonstrated that patients with $\mathrm{AD}$ showed significant increases in their plasma levels of NGF, which were useful markers of disease activity [10]. Moreover, the study of Rapp et al. showed that NGF and brain-derived neurotrophic factors increased in $\mathrm{AD}$ patients [11]. We postulated that the increased plasma concentrations of NGF in patients with $A D$ in this study could be partly derived due to the enhancement, activation, and proliferation of Th2 cells, mast cells, and eosinophils, which were also able to synthesize, store, and release NGF [22, 23]. On the contrary, NGF systemically modulated the allergic response in $\mathrm{AD}$ through interactions with cells of the immuneinflammatory component [10]. However, Schulte-Herbruggen et al. did not show any correlation of NGF with AD severity [9]. Different age group, ethnicity, or laboratory method might account for the disagreement.

It is interesting to discover that cord blood NGF levels were positively although statistically insignificantly correlated with maternal blood, and the mean maternal NGF levels were higher than those of cord blood. This was consistent with a study performed by Haddad et al., which reported that NGF levels were low in newborns compared with adults and had developmental changes [25]. This may also imply that NGF was mainly produced from the mother and might cross the placenta. In addition, children were speculated to get from their mothers a similar pattern of NGF-associated susceptibility to AD.

In our study, there was a positive correlation between maternal self-reported stress during pregnancy and NGF levels. Stress enhances allergen-induced skin weal responses and triggers mast cell degranulation via NGF and VIP [26]. In a study performed by Aloe et al, plasma levels of the NGF were significantly increased in men after the emotional stressor of a parachute [27]. Suckling, which was associated with an inhibited hypothalamic-pituitaryadrenal axis response to stress in women, reduced allergic skin responses and plasma levels of neuropeptide and neurotrophin in lactating women with $\mathrm{AD}$ [28]. Moreover, in a rodent model, stress significantly up-regulated decidual expression of NGF and TrkA (the high-affinity receptor for NGF), suggesting a functional role for NGF in stress-triggered abortion [29]. Taken together, stress was therefore an essential modulator for neuro-immune interactions, especially in AD. NGF might be a good biomarker to evaluate the effects of maternal stress during pregnancy. However, in contrast to our study, Lang et al. reported that NGF serum levels did not change after stress from an academic oral presentation while SchulteHerbrüggen et al. found that there was no association of 
NGF with pregnancy [30, 31]. Another study of this group has also shown that serum NGF level was stable within individuals, but differs considerably between individuals [32]. This discrepancy could possibly be due to different ethnicity, various kinds and quality of the stress, and different study designs of the inter-individual (case-control study) or intra-individual (pre- and post-intervention study) NGF variations. Further studies of different kinds of stress and inter- and intra-individual repeated NGF measurements are warranted.

If emotional stress has an impact on neurotrophin and neuropeptide levels, it might be inferred that neuromediators play a more prominent role in the intrinsic type of $\mathrm{AD}$. However, we found that NGF levels were higher in patients with both intrinsic and extrinsic AD. Raap U et al. also reported that NGF increased in both types of $\mathrm{AD}$ irrespective of the presence of specific sensitization [11]. Because stress can increase serum IgE levels and skews cytokine pattern towards the Th2 type [2], and because both types of $\mathrm{AD}$ display the same clinical features (such as typical morphology, non-specific cutaneous hyperreactivity, and pruritus) and are distinguished only by immunological parameters, it is likely that both types of $\mathrm{AD}$ have a similar pathophysiology and would both elevate NGF levels [1].

The strengths of our study included the nested casecontrol design in the prospective cohort study. Compared with a case-control study, a nested case-control study can reduce recall bias and temporal ambiguity, while compared with a cohort study, it can reduce cost and save time. Our limitation was that not all cases of $\mathrm{AD}$ were diagnosed by dermatologists in this prospective epidemiological study. However, the case ascertainment in the present study has been validated previously vs. clinical examination in other large prospective cohort studies [12-14]. Another limitation was that the maternal NGF level was measured only once in the third trimester of pregnancy. This might not actually be representative of the individual predisposition to sustained high NGF levels throughout gestation, as several measurements taken during pregnancy may be more reliable in providing a better picture of the maternal status. According to previous studies, however, it was reported that serum NGF level was stable within individuals and that NGF level was not altered during normal pregnancy [31, 32]. Furthermore, if measurement error did occur, it tended to be towards the null and the effect of stress exposure was likely to be underestimated.

In conclusion, we observed that maternal and cord blood NGF may serve as a good substitute for IgE in identifying children with a risk of AD. It increased in both intrinsic and extrinsic types of $\mathrm{AD}$ and may be related to maternal stress during pregnancy. Future follow-up studies are warranted to determine whether NGF can predict other allergic diseases.

\section{Acknowledgements}

This study was supported in part by grants from the Bureau of Health Promotion, Department of Health (BHPPHRC-92-4 and DOH93-HP-1702), and the National Science Council (NSC96-2314-B-192 -001) of Taiwan.

\section{References}

1 Park JH, Choi YL, Namkung JH et al. Characteristics of extrinsic vs. intrinsic atopic dermatitis in infancy: correlations with laboratory variables. Br J Dermatol 2006; 155:778-83.

2 Wright RJ, Cohen RT, Cohen S. The impact of stress on the development and expression of atopy. Curr Opin Allergy Clin Immunol 2005; 5:23-9.

3 Arck PC, Slominski A, Theoharides TC, Peters EM, Paus R. Neuroimmunology of stress: skin takes center stage. J Invest Dermatol 2006; 126:1697-704.

4 Raap U, Kapp A. Neuroimmunological findings in allergic skin diseases. Curr Opin Allergy Clin Immunol 2005; 5:419-24.

5 Nockher WA, Renz H. Neurotrophins in allergic diseases: from neuronal growth factors to intercellular signaling molecules. J Allergy Clin Immunol 2006; 117:583-9.

6 Herberth G, Daegelmann C, Weber A et al. Association of neuropeptides with Th1/Th2 balance and allergic sensitization in children. Clin Exp Allergy 2006; 36:1408-16.

7 Gordon DJ, Ostlere LS, Holden CA. Neuropeptide modulation of Th1 and Th2 cytokines in peripheral blood mononuclear leucocytes in atopic dermatitis and non-atopic controls. Br J Dermatol 1997; 137:921-7.

8 Järvikallio A, Harvima IT, Naukkarinen A. Mast cells, nerves and neuropeptides in atopic dermatitis and nummular eczema. Arch Dermatol Res 2003; 295:2-7.

9 Schulte-Herbruggen 0, Folster-Holst R, von Elstermann M, Augustin M, Hellweg R. Clinical relevance of nerve growth factor serum levels in patients with atopic dermatitis and psoriasis. Int Arch Allergy Immunol 2007; 18;144:211-6.

10 Toyoda M, Nakamura M, Makino T, Hino T, Kagoura M, Morohashi M. Nerve growth factor and substance P are useful plasma markers of disease activity in atopic dermatitis. $\mathrm{Br} J$ Dermatol 2002; 147:71-9.

11 Raap U, Werfel T, Goltz C et al. Circulating levels of brain-derived neurotrophic factor correlate with disease severity in the intrinsic type of atopic dermatitis. Allergy 2006; 61:1416-8.

12 Benn CS, Benfeldt E, Andersen PK, Olesen AB, Melbye M, Bjorksten B. Atopic dermatitis in young children: diagnostic criteria for use in epidemiological studies based on telephone interviews. Acta Derm Venereol 2003; 83:347-50.

13 Chan HH, Pei A, Van Krevel C, Wong GWK, Lai CKW. Validation of the Chinese translated version of ISAAC core questions for atopic eczema. Clin Exp Allergy 2001; 31:903.

14 Yamada E, Vanna AT, Naspitz CK, Solé D. International Study of Asthma and Allergies in Childhood (ISAAC): validation of the written questionnaire (eczema component) and prevalence of atopic eczema among Brazilian children. J Investig Allergol Clin Immunol 2002; 12:34-41.

15 Moore MM, Rifas-Shiman SL, Rich-Edwards JW et al. Perinatal predictors of atopic dermatitis occurring in the first six months of life. Pediatrics 2004; 113:468-74. 
16 Edenharter G, Bergmann RL, Bergmann KE et al. Cord blood-IgE as risk factor and predictor for atopic diseases. Clin Exp Allergy 1998; 28:671-8.

17 Kjellman NI. Prediction and prevention of atopic allergy. Allergy 1998; 53:67-71.

18 Eiriksson TH, Sigurgeirsson B, Ardal B, Sigfusson A, Valdimarsson $\mathrm{H}$. Cord blood IgE levels are influenced by gestational age but do not predict allergic manifestations in infants. Pediatr Allergy Immunol 1994; 5:5-10.

19 Varonier HS, Lacourt GC, Assimacopoulos A.Cord serum IgE and early detection of the atopic phenotype: suitable for routine screening? Eur J Pediatr 1991; 150:844-6.

20 Hide DW, Arshad SH, Twiselton R, Stevens M. Cord serum IgE: an insensitive method for prediction of atopy. Clin Exp Allergy 1991; 21:739-43.

21 Hansen LG, Høst A, Halken S et al. Cord blood IgE. II. Prediction of atopic disease. A follow-up at the age of 18 months. Allergy 1992; 47:397-403.

22 Bonini S, Lambiase A, Bonini S, Levi-Schaffer F, Aloe L. Nerve growth factor: an important molecule in allergic inflammation and tissue remodelling. Int Arch Allergy Immunol 1999; 118:159-62.

23 Bonini S, Rasi G, Bracci-Laudiero ML, Procoli A, Aloe L. Nerve growth factor: neurotrophin or cytokine? Int Arch Allergy Immunol 2003; 131:80-4.

24 Fabricant RN, Todaro GJ. Increased serum levels of nerve growth factor in von Recklinghausen's disease. Arch Neurol 1981; 38:401-5.
25 Haddad J, Vilge V, Juif JG et al. Beta-nerve growth factor levels in newborn cord sera. Pediatr Res 1994; 35:637-9.

26 Kimata H. Enhancement of allergic skin wheal responses in patients with atopic eczema/dermatitis syndrome by playing video games or by a frequently ringing mobile phone. Eur J Clin Invest 2003; 33:513-7.

27 Aloe L, Bracci-Laudiero L, Alleva E, Lambiase A, Micera A, Tirassa P. Emotional stress induced by parachute jumping enhances blood nerve growth factor levels and the distribution of nerve growth factor receptors in lymphocytes. Proc Natl Acad Sci USA 1994; 91:10440-4.

28 Kimata H. Suckling reduces allergic skin responses and plasma levels of neuropeptide and neurotrophin in lactating women with atopic eczema/dermatitis syndrome. Int Arch Allergy Immunol 2003; 132:380-3.

29 Tometten M, Klapp BF, Joachim R et al. Nerve growth factor and its functional receptor TrkA are up-regulated in murine decidual tissue of stress-triggered and substance P-mediated abortion. Am J Reprod Immunol 2004; 51:86-93.

30 Lang UE, Anders D, Danker-Hopfe H, Hellweg R. Measurement of nerve growth factor serum concentration in a psychologically stressful situation in men. Stress 2004; 7:39-42.

31 Schulte-Herbrüggen 0, Litzke J, Hornych K et al. Maternal nerve growth factor serum levels in the perinatal period. $J$ Reprod Immunol 2007; 74:170-3.

32 Lang UE, Gallinat J, Danker-Hopfe H, Bajbouj M, Hellweg R. Nerve growth factor serum concentrations in healthy human volunteers: physiological variance and stability. Neurosci Lett 2003; 344:13-6. 